\title{
Impact of sentinel node biopsy on long-term quality of life in breast cancer patients
}

E De Gournay ${ }^{1,8}$, A Guyomard ${ }^{1}$, C Coutant ${ }^{1}$, S Boulet ${ }^{1}$, P Arveux ${ }^{2,3}$, S Causeret ${ }^{1}$, S Gouy ${ }^{1}$, M-M Padeano ${ }^{1}$, C Loustalot ${ }^{1}$, J-M Sauzedde ${ }^{4}, \mathrm{M} \mathrm{Smail}^{5}$, J-P Combier ${ }^{6}$, P Chevillote $^{6}$, C Rosburger ${ }^{6}$, F Bonnetain ${ }^{7}$, J Fraisse ${ }^{1}$ and T S Dabakuyo-Yonli*,2,3,8

\begin{abstract}
${ }^{1}$ Department of surgery/Georges François Leclerc Comprehensive Cancer Care Centre-1 rue Professeur Marion, 21000 Dijon, France; ${ }^{2}$ Biostatistics and Quality of life Unit/Georges François Leclerc Comprehensive Cancer Care Centre-1 rue Professeur Marion, and national quality of life and cancer clinical research platform, 21000 Dijon, France; ${ }^{3}$ EA 4184, Faculty of Medicine, University of Burgundy, 7 boulevard Jeanne d'Arc, 21000 Dijon, France; ${ }^{4}$ Val de Saone private general hospital, 5crs Moreau, 71000 Macon, France; ${ }^{5}$ Sainte Marie private hospital, 4 all St Jean des Vignes, 71100 Chalon sur Saone, France; ${ }^{6}$ Hotel-Dieu hospital, 175 r Mar Foch, 71200 Le Creusot, France and ${ }^{7}$ Methodology and quality of Life in Oncology unit (EA 3181), University Hospital, 2 place Saint Jacques and national quality of life and cancer clinical research platform, 25000 Besançon, France
\end{abstract}

Background: The aim of this study was to assess long-term quality of life (QoL) over a period of 6 years in women with breast cancer (BC) who underwent sentinel lymph node biopsy (SLNB), axillary lymph node dissection (ALND), or SLNB followed by ALND.

Methods: The European Organisation for Research and Treatment of Cancer Quality of Life Questionnaire (EORTC-QLQ)-C30 and the EORTC-QLQ-BR-23 questionnaires were used to assess QoL before surgery, just after surgery, 6, 12 and 72 months later. The longitudinal effect of surgical modalities on QoL was assessed with a mixed model analysis of variance for repeated measurements.

Results: Five hundred and eighteen BC patients were initially included. The median follow-up was 6 years. During the follow-up, 61 patients died. None of the patients of the SLNB group developed lymphedema during follow-up and the relapse rate was similar in the different groups $(P=0.62)$. Before surgery, global health status $(P=0.52)$ and arm symptoms (BRAS) $(P=0.99)$ QoL scores were similar whatever the surgical procedure. The BRAS score $(P=0.0001)$ was better in the SLNB group 72 months after surgery. Moreover, during follow-up, patients treated with SLNB had lower arm symptoms scores than ALND patients and there was no difference for arm symptoms between patients treated with ALND and those treated with SLNB followed by complementary ALND.

Conclusion: Long-term follow-up showed that SLNB was associated with less morbidity than ALND.

Breast cancer $(\mathrm{BC})$ is the most common malignancy in women worldwide. At present, the incidence of BC in Europe is 94.3 per 100000 with a mortality of 26 per 100000 (Ferlay et al, 2007). Owing to BC screening and new adjuvant systemic and/or hormone therapies, survival after BC has improved by $7-11 \%$ over the past few years (Vervoort et al, 2004). Five-year survival in
France is about $80 \%$ (Sant et al, 2009). As overall survival is good for patients with $\mathrm{BC}$, it is important to assess the impact of $\mathrm{BC}$ management (that is, treatment advances) on health-related quality of life (QoL) in patients with BC. Indeed, QoL issues are of interest in $\mathrm{BC}$, because effective methods for detection and treatment have led to an increase in the number of long-term survivors.

\footnotetext{
*Correspondence: Dr TS Dabakuyo-Yonli; E-mail: sdabakuyo@cgfl.fr
}

${ }^{8}$ These authors contributed equally to this work.

Received 5 June 2013; revised 20 September 2013; accepted 1 October 2013; published online 29 October 2013 
Surgical procedures for BC have improved according to the results of randomised trials testing new procedures (Lacour et al, 1983; Maddox et al, 1983; Jacobson et al, 1995; Fisher et al, 2002; McCready et al, 2005). Breast-conserving treatment is now regarded as a standard treatment for early BC and sentinel lymph node biopsy (SLNB) became an alternative to axillary lymph node dissection (ALND) in the 1990s (McCready et al, 2005). Sentinel lymph node biopsy is a proven safe surgical method and causes less morbidity than ALND (Krag et al, 1993; Burak et al, 2002) with a smaller impact on QoL (Veronesi et al, 2003; Purushotham et al, 2005; Mansel et al, 2006; Del Bianco et al, 2008; Dabakuyo et al, 2009; Gill, 2009; Wang et al, 2011). Moreover, ALND may result in significant arm morbidity (Kuehn et al, 2000), including wound infections, seroma formation, damage to sensory and motor nerves, pain, loss of strength, impaired range of shoulder motion (Kissin et al, 1986), and lymphedema, which is of particular concern for women undergoing axillary surgery. Lymphedema is the most common long-term morbidity following axillary surgery and it may be associated with decreased limb mobility and functional problems, pain, sleep disturbance, anxiety, depression, poor wound healing and increased risk of infection (Erickson et al, 2001). To our knowledge, no prospective study has assessed QoL after axillary surgery for BC with a long follow-up.

The aim of this study was to assess long-term QoL over a period of 6 years in women with BC who underwent ALND, SLNB or SLNB followed by ALND.

\section{PATIENTS AND METHODS}

Patients. The design of this study has been described elsewhere (Dabakuyo et al, 2009). Briefly, it was a prospective multicentre study that include all women operated on for BC as the primary treatment in five hospitals of the Côte d'Or and Saône et Loire (French counties). Cases were registered from January 2005 to January 2006. Since the American Society of Clinical Oncology (ASCO) published recommendations for sentinel lymph node biopsy in early-stage BC in 2005 (Lyman et al, 2005), it was therefore impossible to conduct a randomised trial. The study was thus designed to assess routine surgical procedures, and the choice between ALND and SLNB was made by surgeons according to ASCO recommendations and according to their usual practice in their centre. A third group was defined for patients who underwent SLNB with additional lymphadenectomy.

Written informed consent was obtained from every participant in accordance with a protocol approved by local ethics committees ('Comité de Protection des Personnes' de Bourgogne).

Studied variables and end points. QoL was assessed using the European Organisation for Research and Treatment of Cancer Quality of Life Questionnaire (EORTC-QLQ)-C30 and the EORTC-QLQ-BR23 (Aaronson et al, 1993). QoL scores vary from 0 (worst) to 100 (best) for the functional and global health status (GHS) parameters and from 0 (best) to 100 (worst) for symptoms parameters. A five-point difference in QoL scores is considered the minimum clinically significant difference (Osoba et al, 1998). The GHS, the arm (BRAS) and breast (BRBS) symptoms scores were targeted for analyses.

Follow-up. The QoL was assessed by the patients according to a time-driven design: before surgery, just after surgery and 6 and 12 months later. In addition, a final assessment of Qol was done in summer 2011 (about 6 years after the surgery).

Clinical variables such as age, administration and duration of the hormone replacement therapy, tumour size (categorised into three classes: $\leqslant 10 \mathrm{~mm}$ (T1mic, T1a and T1b), 11-20 mm (T1c), $>20 \mathrm{~mm}(\geqslant \mathrm{~T} 2)$ ), tumour histology, c-erb-2 status, the Scarff Bloom and Richardson (SBR) grade and hormone receptor status (either oestrogen or progesterone) were recorded at the time of surgery. At the time the QoL data were updated, information about treatments (chemotherapy, radiotherapy and hormone therapy), the occurrence of lymphedema or breast tumour recurrence, the type of recurrence, as well as the type of surveillance since the diagnosis (regular with one consultation with a mammogram every year or irregular, with less than one consultation with a mammogram every year) were also retrospectively collected.

Statistical methods. Continuous variables were described by means, standard deviations (s.d.), medians and ranges, while qualitative variables were given as percentages. The characteristics of patients who answered the questionnaire during summer 2011 and those who did not were compared using the Pearson's $\chi^{2}$-test for qualitative variables and the Student's $t$-test or Mann-Whitney test for quantitative variables. For these patients, the QoL before updating was also compared using Mann-Whitney tests.

At baseline, patients' clinical characteristics were compared according to the surgical procedure used. The Kruskal-Wallis nonparametric test was used for quantitative variables and the Pearson's $\chi^{2}$-test for qualitative variables.

For each surgical procedure, QoL scores were described at each follow-up time by means, s.d., medians and ranges. The Kruskal-Wallis test was used to compare scores according to the surgical procedure using the Bonferroni correction for multiple comparisons $\left(\alpha^{\prime}=\alpha / n\right.$ with $n=$ number of comparisons made). QoL scores were also described at each follow-up time in the subset of patients with the same favourable prognostic characteristics (T1-T2 and positive hormone receptor status).

Patients' missing-score profiles were then generated to study their impact on QoL scores. Four profiles were studied according to missing-score patterns:

\section{- Patients without missing scores}

- Patients with drop-out scores: when a score was missing at one time of the follow-up, all following scores were inevitably missing (patients lost to follow-up or dead)

- Patients with intermittent missing scores: missing score occurring at any time of the follow-up between two existing scores

- Patients with all scores missing

Patients' missing-score profiles were compared according to the type of surgery to determine whether the patterns of missing data were different depending on the type of surgery. Finally, a mixed model analysis of variance for repeated measurements was applied for each score to assess the impact of the surgical procedure on QoL whatever the follow-up and to test longitudinal change of QoL whatever the surgical procedure. Co-variables were entered as classification variables in the model. Based on the Akaike's information criterion (AIC) (Akaike and Hirotugu, 1974), a compound symmetry covariance structure was chosen in all analyses. Analyses were adjusted on the variables distributed differently depending on the type of surgical procedure as these may confound the results. The interaction between the surgical procedure and the follow-up time and the effect of the patient's profile on QoL were also checked.

All reported $P$-values are two sided. The statistical significance level was set at $P<0.05$. Analyses were done using SAS (version 9.3).

\section{RESULTS}

Population. A pragmatic prospective multicentre study was conducted in five hospitals of the Côte d'Or and Saone et Loire (French counties). All of the women undergoing breast surgery as 
Table 1. Clinical and pathological features according to surgery modalities

ALND

SLNB

$\mathrm{SLNB}+\mathrm{ALND}^{\mathrm{a}}$

\begin{tabular}{|c|c|c|c|c|c|c|c|}
\hline Variables & $\mathbf{N}$ & $\%$ & $\mathbf{N}$ & $\%$ & $\mathbf{N}$ & $\%$ & $\boldsymbol{P}$-value \\
\hline Hospital & & & & & & & $<0.0001$ \\
\hline CGFL & 143 & 86.7 & 103 & 59.5 & 37 & 86.0 & \\
\hline Private hospital of Dijon & 17 & 10.3 & 24 & 13.9 & 5 & 11.6 & \\
\hline Le Creusot & 0 & 0.0 & 17 & 9.8 & 0 & 0.0 & \\
\hline Chalon sur Saône & 4 & 2.4 & 14 & 8.1 & 1 & 2.3 & \\
\hline Macon & 1 & 0.6 & 15 & 8.7 & 0 & 0.0 & \\
\hline Hormone status & & & & & & & 0.04 \\
\hline Premenopausal & 43 & 26.1 & 26 & 15.0 & 9 & 20.9 & \\
\hline Postmenopausal & 122 & 73.9 & 146 & 84.4 & 34 & 79.1 & \\
\hline Unknown & 0 & 0.0 & 1 & 0.6 & 0 & 0.0 & \\
\hline HRT & & & & & & & 0.08 \\
\hline Yes & 34 & 20.6 & 45 & 26.0 & 6 & 14.0 & \\
\hline No & 106 & 64.2 & 96 & 55.5 & 33 & 76.7 & \\
\hline Unknown & 25 & 15.2 & 32 & 18.5 & 4 & 9.3 & \\
\hline Tumour histology & & & & & & & 0.001 \\
\hline Invasive ductal & 134 & 81.2 & 133 & 76.9 & 37 & 86.0 & \\
\hline Invasive lobular & 17 & 10.3 & 9 & 5.2 & 3 & 7.0 & \\
\hline In situ & 6 & 3.6 & 23 & 13.3 & 0 & 0.0 & \\
\hline Medullary cancer & 1 & 0.6 & 0 & 0 & 1 & 2.3 & \\
\hline micro-invasive cancer & 1 & 0.6 & 1 & 0.6 & 1 & 2.3 & \\
\hline Unknown & 6 & 3.6 & 7 & 4.0 & 1 & 2.3 & \\
\hline SBR Grade & & & & & & & $<0.0001$ \\
\hline 1 & 32 & 19.4 & 69 & 39.9 & 10 & 23.3 & \\
\hline 2 & 64 & 38.8 & 56 & 32.4 & 21 & 48.8 & \\
\hline 3 & 52 & 31.5 & 19 & 11.0 & 10 & 23.3 & \\
\hline Unknown & 17 & 10.3 & 29 & 16.8 & 2 & 4.7 & \\
\hline C-erb-2 status & & 0.0 & & 0.0 & & 0.0 & 0.34 \\
\hline Positive & 25 & 15.2 & 14 & 8.1 & 4 & 9.3 & \\
\hline Negative & 121 & 73.3 & 104 & 60.1 & 36 & 83.7 & \\
\hline Unknown & 19 & 11.5 & 55 & 31.8 & 3 & 7.0 & \\
\hline Hormone receptor status & & & & & & & 0.95 \\
\hline Positive & 120 & 72.7 & 113 & 65.3 & 33 & 76.7 & \\
\hline Negative & 25 & 15.2 & 22 & 12.7 & 6 & 14.0 & \\
\hline Unknown & 20 & 12.1 & 38 & 22.0 & 4 & 9.3 & \\
\hline Treatments & & 0.0 & & 0.0 & & 0.0 & \\
\hline Surgery & & & & & & & $<0.0001$ \\
\hline Lumpectomy & 88 & 53.3 & 155 & 89.6 & 42 & 97.7 & \\
\hline Mastectomy & 77 & 46.7 & 17 & 9.8 & 1 & 2.3 & \\
\hline Unknown & 0 & 0.0 & 1 & 0.6 & 0 & 0.0 & \\
\hline Adjuvant chemotherapy & & & & & & & $<0.0001$ \\
\hline Yes & 111 & 67.3 & 28 & 16.2 & 28 & 65.1 & \\
\hline No & 54 & 32.7 & 141 & 81.5 & 15 & 34.9 & \\
\hline Unknown & 0 & 0.0 & 4 & 2.3 & 0 & 0.0 & \\
\hline Radiotherapy & & & & & & & 0.16 \\
\hline Yes & 139 & 84.2 & 149 & 86.1 & 41 & 95.3 & \\
\hline No & 26 & 15.8 & 23 & 13.3 & 2 & 4.7 & \\
\hline Unknown & 0 & 0.0 & 1 & 0.6 & 0 & 0.0 & \\
\hline
\end{tabular}




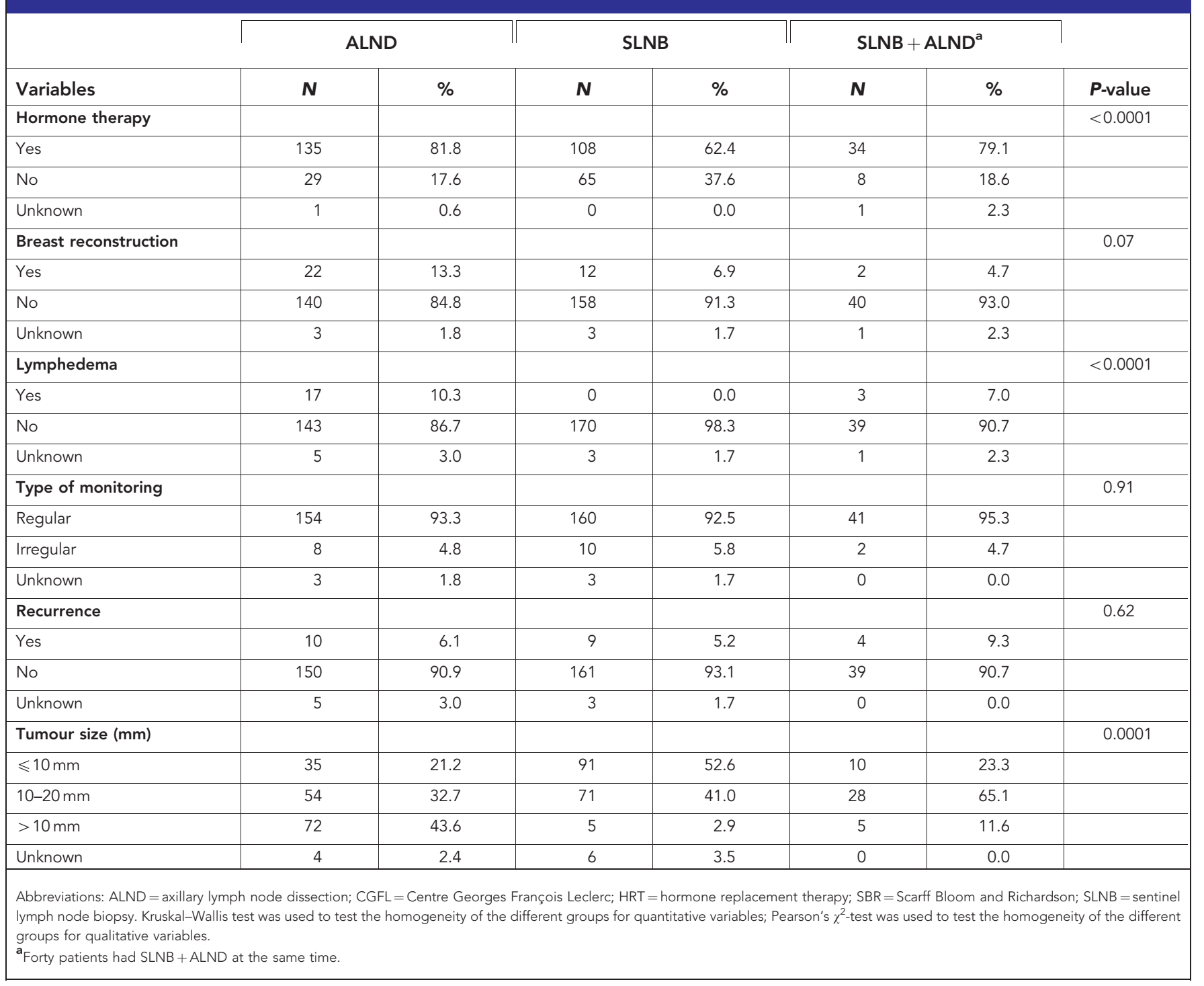

the primary treatment were eligible. Patients with synchronous bilateral BC were excluded. Cases were registered from January 2005 to January 2006. From 1 January 2005 to 1 January 2006, 518 BC patients were initially included. In July 2011, when the QoL data were updated, $61(11.8 \%)$ patients had died, $9(1.7 \%)$ were lost to follow-up. For patients who had died, 44 (72.1\%), 8 (13.1\%) and $9(14.8 \%)$ had been treated by ALND, SLNB and SLNB + ALND, respectively.

QoL questionnaires were sent to 448 patients. Of these, 381 (85\%) answered and were thus retained for the analyses. For this population, the median follow-up was 6 years $(1.7 ; 6.6), 365$ patients $(95.8 \%)$ had small tumours $(\leqslant 50 \mathrm{~mm}), 6$ patients had tumours larger than $50 \mathrm{~mm}(1.6 \%)$ and for 10 patients $(2.6 \%)$ the information about the tumour size was missing. The mean tumour size $(P<0.0001)$ was: $21 \mathrm{~mm}($ s.d. $=14), 11 \mathrm{~mm}($ s.d. $=10)$ and $15 \mathrm{~mm}($ s.d. =6) for the ALND, SLNB and SLNB + ALND groups, respectively, while the mean age at diagnosis $(P=0.18)$ was 58 $($ s.d. $=12), 60($ s.d. $=11)$ and $59($ s.d. $=11)$, respectively. Among the study population, 165 patients (43\%) underwent ALND, 173 patients (45\%) had SLNB and $43(11 \%)$ patients had SLNB + ALND. For 40 (93\%) of these 43 patients, SLNB was followed by immediate complementary ALND. The clinical and pathological features of the three groups of patients are presented in Table 1. Sentinel lymph node biopsy was more often performed in patients with small tumours, and none of the patients of the SLNB group had lymphedema. Patients who underwent SLNB were also more often treated with conservative surgery $(P<0.0001)$, without adjuvant chemotherapy $(P<0.0001)$ and without adjuvant hormone therapy $(P<0.0001)$.

Comparison of the features of the patients who completed and those who did not complete the questionnaire at 72 months. The responders and the non-responders were different only for the hospital $(P=0.007)$. All other characteristics were similar: type of axillary surgery (ALND, SLNB, SLNB + ALND) $(P=0.579)$, the occurrence of lymphedema $(P=0.41)$, breast reconstruction $(P=0.18)$, the type of surveillance $(P=0.81)$, the tumour recurrence $(P=0.08)$, age $(P=0.93)$, the treatments: surgery (lumpectomy, mastectomy) $(P=0.95)$, adjuvant chemotherapy $(P=0.27)$, radiotherapy $(P=0.31)$, hormone therapy $(P=0.65)$. In addition, the QoL scores before, after, at 6 and 12 months after the surgery in the two groups were comparable.

QoL scores according to the surgical procedure. Patients' missing-score profiles were not different according to the surgical procedure. Indeed, there was no difference between the types of surgery for the proportions of patients without missing scores, with drop-out scores, with intermittent missing scores, with all scores 


\begin{tabular}{|c|c|c|c|c|c|c|c|}
\hline & \multicolumn{2}{|c|}{$\begin{array}{l}\text { ALND group } \\
(\boldsymbol{N}=165)\end{array}$} & \multicolumn{2}{|c|}{$\begin{array}{l}\text { SLNB group } \\
(N=173)\end{array}$} & \multicolumn{2}{|c|}{$\begin{array}{c}\text { SLNB }+ \text { ALND group }{ }^{a} \\
(N=43)\end{array}$} & \multirow[t]{2}{*}{$\begin{array}{c}\text { Fisher's exact } \\
\boldsymbol{P} \text {-value }\end{array}$} \\
\hline & $\mathbf{N}$ & $\%$ & $\mathbf{N}$ & $\%$ & $\mathbf{N}$ & $\%$ & \\
\hline GHS & & & & & & & 0.8 \\
\hline No missing scores & 67 & 41 & 76 & 44 & 16 & 37 & \\
\hline Drop-out scores & 3 & 2 & 2 & 1 & 1 & 2 & \\
\hline Intermittent missing scores & 95 & 58 & 95 & 55 & 26 & 60 & \\
\hline No values & 0 & 0 & 0 & 0 & 0 & 0 & \\
\hline BRAS & & & & & & & 0.81 \\
\hline No missing scores & 67 & 41 & 77 & 45 & 16 & 37 & \\
\hline Drop-out scores & 2 & 1 & 1 & 1 & 0 & 0 & \\
\hline Intermittent missing scores & 96 & 58 & 94 & 54 & 27 & 63 & \\
\hline No values & 0 & 0 & 1 & 1 & 0 & 0 & \\
\hline BRBS & & & & & & & 0.51 \\
\hline No missing scores & 85 & 52 & 87 & 50 & 26 & 60 & \\
\hline Drop-out scores & 2 & 1 & 0 & 0 & 0 & 0 & \\
\hline Intermittent missing scores & 77 & 47 & 86 & 50 & 17 & 40 & \\
\hline No values & 1 & 1 & 0 & 0 & 0 & 0 & \\
\hline
\end{tabular}

missing for GHS $(P=0.8)$, BRAS $(P=0.81)$ and BRBS $(P=0.51)$ scores (Table 2).

Before surgery, GHS $(P=0.52)$ and BRAS $(P=0.99)$ QoL scores were similar whatever the surgical procedure (Table 3$)$. There were no differences for GHS and BRBS according to the surgical procedure just after surgery, 6 months later, 12 months later or 72 months later (Table 3, Figures 1a and c). However, BRAS scores were better in the SLNB group after the surgery $(P=0.004), 6$ months later $(P=0.001), 12$ months later $(0.0001)$ and 72 months later $(P=0.0001)$ (Figure 1b). Two-by-two comparison with the Bonferroni correction (statistical significance level $P<0.02$ ) showed significantly better BRAS scores in the SLNB group than in the ALND and SLNB + ALND groups at 6 months $(P=0.0003$ and $P=0.01$, respectively) and 12 months $(P<0.0001$ and $P=0.002$, respectively). After the surgery $(P=0.0006)$ and at 72 months $(P<0.0001)$, BRAS scores were significantly different only between the SLNB and ALND groups.

At 72 months, the body image (BRBI) score was different according to the surgical procedure $(P=0.0005)$. Two-by-two comparison with the Bonferroni correction confirmed that the BRBI score was better in the SLNB group than in the ALND group $(P=0.0001)$. Moreover, at 72 months, two-by-two comparison with the Bonferroni correction showed that the future perspectives $(P=0.0096)$, the systemic therapy side effects $(P=0.0097)$ and upset by hair loss $(P=0.0008)$ QoL scores were better in the SLNB group than in the ALND group.

Of the studied population, 258 (68\%) had the most favourable prognostic characteristics (tumour size smaller than $50 \mathrm{~mm}$ (T1-T2) and positive hormone receptor status). Comparisons of QoL scores in these patients according to the surgical procedure showed similar results to those obtained in the whole population. Indeed, BRAS scores were also better in the SLNB group after the surgery $(P=0.006), 12 \quad(P=0.007)$ and 72 months later $(P=0.0001)$. Scores for body image $(P=0.002)$ and upset by hair loss $(P=0.002)$ were also better in SLNB group 72 months after surgery.
Longitudinal GHS QoL scores. There was no significant effect of the patients' profiles $(P=0.15)$ on the GHS scores and there was no interaction between the follow-up and the type of surgery $(P=0.22)$. In addition, the hospital $(P=0.92)$, the hormone status $(P=0.75)$, the SBR grade $(P=0.28)$, the treatments: type of surgery (lumpectomy, mastectomy) $(P=0.26)$, adjuvant chemotherapy $(P=0.36)$, hormone therapy $(P=0.20)$, the occurrence of lymphedema $(P=0.55)$, which were different depending on the type of axillary surgery, had no independent effect on the GHS scores. Only the tumour size $(P=0.04)$ affected GHS scores. Indeed, women with tumour smaller than $10 \mathrm{~mm}$ had higher GHS scores $(\mathrm{MD}=7.2)$ than did women with tumours larger than $20 \mathrm{~mm}(P=0.01)$.

Whatever the surgical procedure, GHS scores decreased after surgery, started increasing 6 months later until 12 months but decreased again 72 months later. Whatever the follow-up, the surgical procedure had no impact on GHS scores $(P=0.0726)$ (Table 4).

Longitudinal BRAS QoL scores. There was no significant effect of the patients' profiles $(P=0.16)$ on the BRAS scores. In addition, the hospital $(P=0.92)$, the hormone status $(P=0.32)$, the SBR grade $(P=0.38)$, the treatments: type of surgery (lumpectomy, mastectomy) $(P=0.55)$, adjuvant chemotherapy $(P=0.35)$, the tumour size $(P=0.81)$, which were different depending on the type of axillary surgery, had no independent effect on the BRAS scores. Patients treated without hormone therapy had lower scores for arms symptoms than those treated with hormone therapy $\mathrm{MD}=-3.91(P=0.049)$. The occurrence of lymphedema $(P<0.0001)$ also affected BRAS scores. Indeed, in women without lymphedema during follow-up, arms symptoms scores were lower $(\mathrm{MD}=-13.4, P<0.0001)$.

Whatever the surgical procedure, BRAS scores increased after the surgery $(\mathrm{MD}=12.6$, s.d. $=2.2, P<0.0001), 6$ months later $(\mathrm{MD}=12.6$, s.d. $=2.1, \quad P<0.0001), 12$ months later $(\mathrm{MD}=13.2$, s.d. $=2.1$, $P<0.0001)$ and 72 months later $(\mathrm{MD}=15.5$, s.d. $=2.1, P<0.0001)$. 
Table 3. QoL scores according to the axillary surgery modalities

\begin{tabular}{|c|c|c|c|c|c|c|c|c|c|c|}
\hline & \multicolumn{3}{|c|}{ ALND $(N=165)$} & \multicolumn{3}{|c|}{$\operatorname{SLNB}(N=173)$} & \multicolumn{3}{|c|}{$\mathrm{SLNB}+\operatorname{ALND}^{\mathrm{a}}(\mathbf{N}=43)$} & \multirow[b]{2}{*}{$P$-value } \\
\hline Variables & $N$ & $\begin{array}{l}\text { Mean } \\
\text { (s.d.) }\end{array}$ & $\begin{array}{c}\text { Median } \\
\text { (Min-Max) }\end{array}$ & $N$ & $\begin{array}{l}\text { Mean } \\
\text { (s.d.) }\end{array}$ & $\begin{array}{c}\text { Median } \\
\text { (Min-Max) }\end{array}$ & $\mathbf{N}$ & $\begin{array}{l}\text { Mean } \\
\text { (s.d.) }\end{array}$ & $\begin{array}{c}\text { Median } \\
\text { (Min-Max) }\end{array}$ & \\
\hline \multicolumn{11}{|l|}{ GHS } \\
\hline Before surgery & 93 & 74 (19) & $75(17-100)$ & 119 & $76(17)$ & $83(33-100)$ & 25 & 79 (19) & $83(33-100)$ & 0.52 \\
\hline After surgery & 114 & $68(19)$ & $67(8-100)$ & 126 & $72(18)$ & $71(17-100)$ & 28 & $65(23)$ & $67(0-100)$ & 0.27 \\
\hline 6 Months after surgery & 147 & $72(18)$ & $75(17-100)$ & 137 & $73(19)$ & $75(0-100)$ & 39 & $69(19)$ & $67(33-100)$ & 0.36 \\
\hline 12 Months after surgery & 144 & 75 (18) & $83(25-100)$ & 136 & $77(18)$ & $83(25-100)$ & 36 & $70(19)$ & $67(25-100)$ & 0.1 \\
\hline 72 Months after surgery & 160 & $72(22)$ & $75(0-100)$ & 170 & $70(20)$ & $67(0-100)$ & 41 & $65(22)$ & $67(17-100)$ & 0.15 \\
\hline \multicolumn{11}{|l|}{ BRAS } \\
\hline Before surgery & 93 & $6(9)$ & $0(0-33)$ & 120 & $7(12)$ & $0(0-67)$ & 25 & $7(13)$ & $0(0-56)$ & 0.99 \\
\hline After surgery & 115 & 19 (18) & $11(0-89)$ & 125 & $12(15)$ & $11(0-67)$ & 28 & $15(17)$ & $11(0-67)$ & 0.004 \\
\hline 6 Months after surgery & 146 & $20(20)$ & $11(0-100)$ & 138 & $13(16)$ & $11(0-100)$ & 39 & $21(20)$ & $11(0-78)$ & 0.001 \\
\hline 12 Months after surgery & 145 & $20(20)$ & $11(0-100)$ & 136 & $11(15)$ & $0(0-78)$ & 36 & $19(17)$ & $17(0-56)$ & 0.0001 \\
\hline 72 Months after surgery & 159 & $23(26)$ & $11(0-100)$ & 171 & $12(19)$ & $0(0-100)$ & 42 & $17(24)$ & $11(0-100)$ & 0.0001 \\
\hline \multicolumn{11}{|l|}{ BRBS } \\
\hline After surgery & 102 & $19(15)$ & $17(0-67)$ & 116 & $21(17)$ & $17(0-83)$ & 28 & $17(17)$ & $17(28-58)$ & 0.33 \\
\hline 6 Months after surgery & 146 & $22(20)$ & $17(0-92)$ & 138 & $22(16)$ & $17(0-89)$ & 40 & $26(23)$ & $17(0-100)$ & 0.64 \\
\hline 12 Months after surgery & 144 & $19(18)$ & $17(0-100)$ & 136 & $19(16)$ & $17(0-92)$ & 37 & $19(16)$ & $17(0-58)$ & 0.91 \\
\hline 72 Months after surgery & 160 & $19(20)$ & $17(0-92)$ & 173 & $16(18)$ & $8(0-92)$ & 42 & $17(20)$ & $17(0-92)$ & 0.63 \\
\hline \multicolumn{11}{|l|}{ Other scores at 72 months } \\
\hline Physical functioning & 164 & $83(17)$ & $87(27-100)$ & 172 & $86(16)$ & $93(27-100)]$ & 43 & $82(19)$ & $87(0-100)$ & 0.11 \\
\hline Role functioning & 164 & $80(26)$ & $83(0-100)$ & 173 & $85(22)$ & $100(0-100)$ & 42 & $82(22)$ & $83(0-100)$ & 0.13 \\
\hline Emotional functioning & 161 & $75(24)$ & $75(0-100)$ & 170 & $76(23)$ & $83(0-100)$ & 42 & $73(22)$ & $75(8-100)$ & 0.53 \\
\hline Cognitive functioning & 161 & $84(21)$ & $83(0-100)$ & 172 & $84(21)$ & $100(0-100)$ & 42 & $77(26)$ & $83(0-100)$ & 0.27 \\
\hline Social functioning & 159 & $85(26)$ & $100(0-100)$ & 170 & $89(21)$ & $100(0-100)$ & 42 & $83(24)$ & $100(17-100)$ & 0.33 \\
\hline Fatigue & 162 & $28(25)$ & $22(0-100)$ & 172 & $27(23)$ & $22(0-100)$ & 42 & $31(24)$ & $33(0-100)$ & 0.51 \\
\hline Nausea and vomiting & 162 & $6(15)$ & $0(0-100)$ & 171 & $3(10)$ & $0(0-67)$ & 42 & $3(16)$ & $0(0-100)$ & 0.51 \\
\hline Pain & 164 & $21(26)$ & $17(0-100)$ & 172 & $18(24)$ & $33(0-100)$ & 42 & $20(22)$ & $17(0-67)$ & 0.5 \\
\hline Dyspnoea & 160 & $19(26)$ & $0(0-100)$ & 171 & $20(27)$ & $0(0-100)$ & 41 & $21(29)$ & $0(0-100)$ & 0.96 \\
\hline Insomnia & 158 & $28(29)$ & $33(0-100)$ & 169 & $31(33)$ & $33(0-100)$ & 41 & $41(33)$ & $33(0-100)$ & 0.12 \\
\hline Appetite loss & 160 & $10(23)$ & $0(0-100)$ & 171 & $6(17)$ & $0(0-100)$ & 40 & $5(16)$ & $0(0-67)$ & 0.38 \\
\hline Constipation & 162 & $17(28)$ & $0(0-100)$ & 170 & $16(25)$ & $0(0-100)$ & 42 & $13(21)$ & $0(0-67)$ & 0.96 \\
\hline Diarrhoea & 159 & $8(16)$ & $0(0-67)$ & 169 & $7(15)$ & $0(0-67)$ & 40 & $9(18)$ & $0(0-67)$ & 0.95 \\
\hline Financial difficulties & 159 & $7(20)$ & $0(0-100)$ & 169 & $7(18)$ & $0(0-100)$ & 42 & $6(15)$ & $0(0-67)$ & 0.97 \\
\hline \multicolumn{11}{|l|}{ QLQ-BR23 } \\
\hline Body image & 159 & $71(32)$ & $83(0-100)$ & 168 & $83(25)$ & $92(0-100)$ & 40 & $76(27)$ & $83(0-100)$ & 0.0005 \\
\hline Sexual functioning & 145 & $19(24)$ & $0(0-100)$ & 152 & $18(23)$ & $0(0-83)$ & 38 & $16(20)$ & $0(0-67)$ & 0.77 \\
\hline Sexual enjoyment & 68 & $46(33)$ & $33(0-100)$ & 65 & $53(33)$ & $67(0-100)$ & 17 & $45(29)$ & $33(0-100)$ & 0.44 \\
\hline Future perspectives & 156 & $57(35)$ & $67(0-100)$ & 166 & $67(30)$ & $67(0-100)$ & 37 & $66(33)$ & $67(0-100)$ & 0.04 \\
\hline Systemic therapy side effects & 162 & $19(20)$ & $14(0-95)$ & 170 & $13(14)$ & $10(0-81)$ & 41 & $18(15)$ & $14(0-81)$ & 0.01 \\
\hline Upset by hair loss & 63 & $56(41)$ & $67(0-100)$ & 45 & $30(34)$ & $33(0-100)$ & 21 & $38(41)$ & $33(0-100)$ & 0.004 \\
\hline
\end{tabular}

A quantitative interaction was seen between the follow-up and the type of surgery $(P=0.04)$. In fact, patients treated with SLNB had lower symptoms scores during the follow-up than patients treated with ALND. BRAS scores were lower in the SLNB group than in the ALND group after the surgery $(\mathrm{MD}=-7.6$, s.d. $=3.1$, $P=0.01), \quad 6$ months later $(\mathrm{MD}=-6.1, \quad$ s.d. $=3, \quad P=0.04)$, 12 months later $(\mathrm{MD}=-9$, s.d. $=3, P=0.003)$ and 72 months later $(\mathrm{MD}=-10.8$, s.d. $=2.9, P=0.0002)$. However, BRAS scores were not significantly different between ALND and SLNB + ALND whatever the follow-up time (Table 5).
Longitudinal BRBS QoL scores. There was no significant effect of the patients' profiles $(P=0.51)$ on the BRBS scores and there was no interaction between the follow-up and the type of surgery $(P=0.2)$. In addition, the hospital $(P=0.86)$, the SBR grade $(P=0.75)$, the treatments: type of surgery (lumpectomy, mastectomy) $(P=0.78)$, adjuvant chemotherapy $(P=0.51)$, hormone therapy $(P=0.54)$, the occurrence of lymphedema $(P=0.56)$, the tumour size $(P=0.45)$ had no independent effect on the GHS scores. Only the hormone status $(P=0.03)$ affected BRBS scores. 


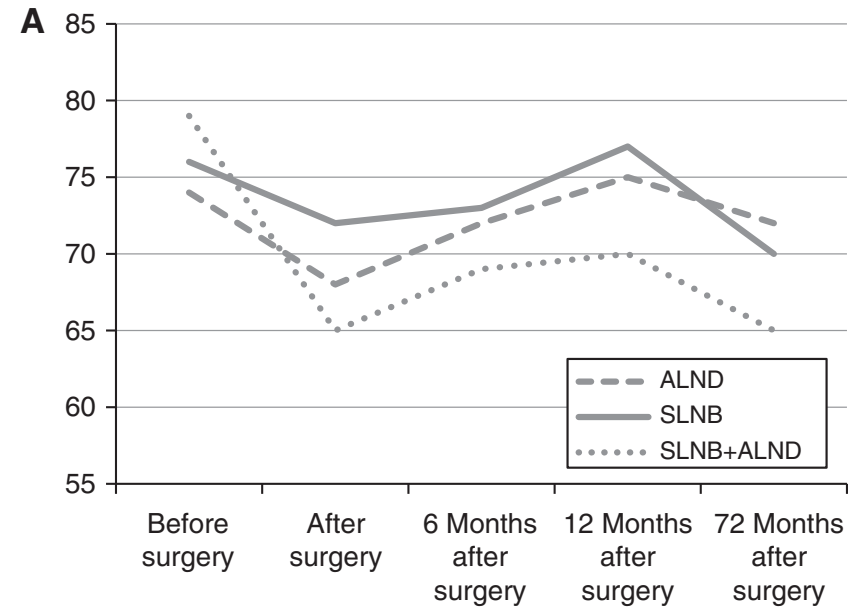

B
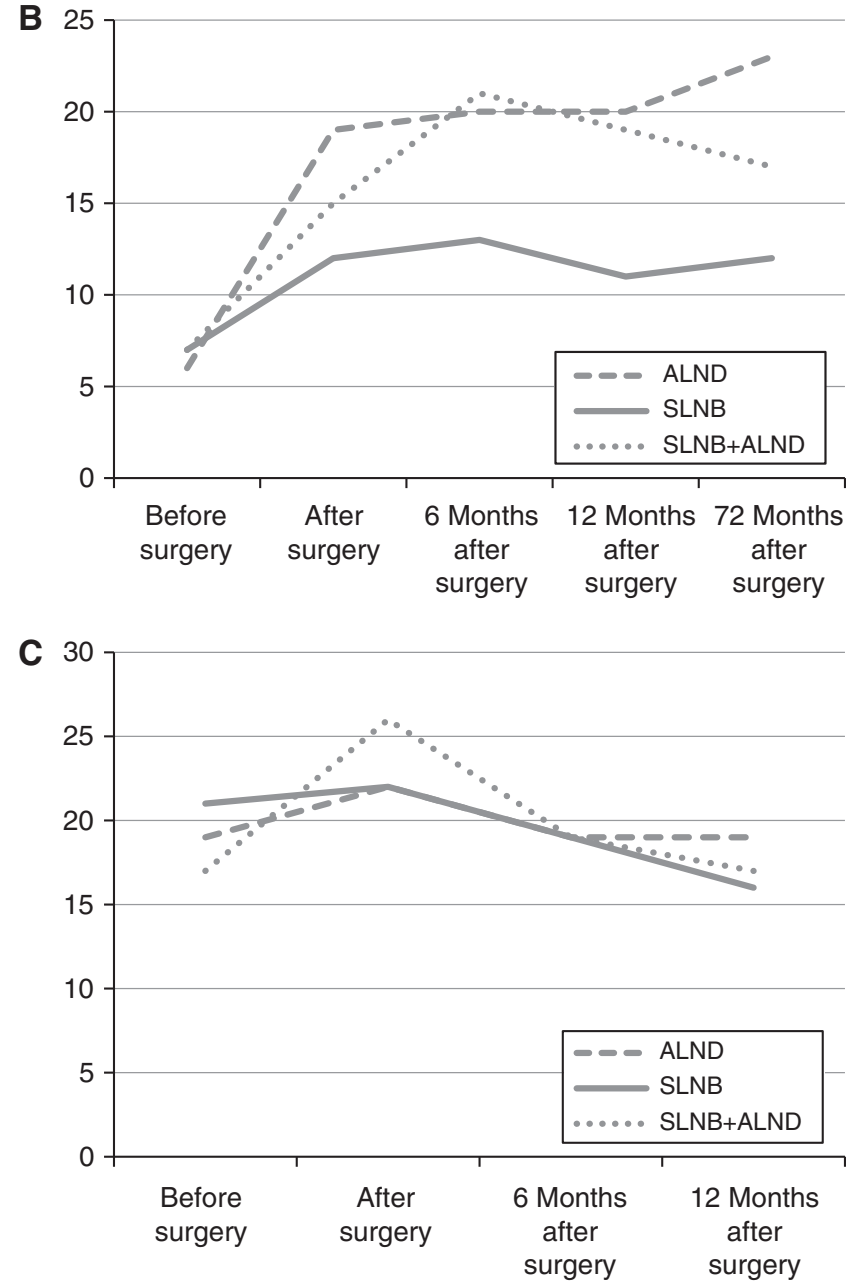

Figure 1. Mean quality of life scores according to the follow-up time and the type of surgery: (A) global health; (B) arm symptoms; (C) breast symptoms.

Whatever the surgical procedure, BRBS scores were higher 6 months than immediately after the surgery $(P=0.001)$. However, BRBS scores 12 months after surgery $(P=0.52)$ and 72 months after surgery $(P=0.41)$ were not different to post-surgery scores (Table 4).

Whatever the follow-up, the axillary surgical procedure had no impact on BRBS QoL scores $(P=0.84)$ (Table 4$)$, and premenopausal women were more likely than postmenopausal women to have high breast symptoms scores $(\mathrm{MD}=4.4, P=0.03)$.
Table 4. Long-term effect of surgical procedure and factors affecting global health and breast symptoms in breast cancer patient

\begin{tabular}{|c|c|c|c|c|}
\hline & \multicolumn{2}{|c|}{ Global health } & \multicolumn{2}{|c|}{ Breast symptoms } \\
\hline & Beta (s.e.) & $\boldsymbol{P}$ & Beta (s.e.) & $\boldsymbol{P}$ \\
\hline Constant & $74(6.4)$ & $<0.0001$ & $19.8(6.4)$ & 0.002 \\
\hline Follow-up & & $<0.0001^{\mathrm{a}}$ & & $<0.0001^{a}$ \\
\hline Before surgery & Reference & & & \\
\hline After surgery & $-6.7(1.5)$ & $<0.0001$ & Reference & \\
\hline 6 Months after surgery & $-4(1.4)$ & 0.005 & $4.4(1.4)$ & 0.0012 \\
\hline 12 Months after surgery & $-1.2(1.4)$ & 0.4 & $0.9(1.4)$ & 0.52 \\
\hline 72 Months after surgery & $-5.3(1.4)$ & 0.0002 & $-1.1(1.3)$ & 0.41 \\
\hline Axillary dissection type & & $0.0726^{\mathrm{a}}$ & & $0.84^{\mathrm{a}}$ \\
\hline ALND & Reference & & Reference & \\
\hline SLNB & $-1.8(2.5)$ & 0.48 & $-1.1(2.4)$ & 0.6323 \\
\hline SLNB + ALND & $-6.4(2.8)$ & 0.02 & $0.3(2.7)$ & 0.9075 \\
\hline Tumour size & & $0.0371^{\mathrm{a}}$ & & \\
\hline$>20 \mathrm{~mm}$ & Reference & & & \\
\hline $10-20 \mathrm{~mm}$ & $3.4(2.4)$ & 0.16 & & \\
\hline$\leqslant 0 \mathrm{~mm}$ & $7.2(2.8)$ & 0.01 & & \\
\hline Hormone status & & & & 0.03 \\
\hline Postmenopausal & & & Reference & \\
\hline Premenopausal & & & $4.4(2)$ & \\
\hline \multicolumn{5}{|c|}{$\begin{array}{l}\text { Abbreviations: ALND = axillary lymph node dissection; SLNB = sentinel lymph node biopsy; } \\
\text { s.e. = standard error. NB: Multivariable analyses were adjusted for hospitals, hormonal } \\
\text { status, the Scarff Bloom and Richardson grade, treaments: the type of surgery, adjuvant } \\
\text { chemotherapy, hormone therapy, the occurrence of lymphedema and tumour size. } \\
\text { a Overall effect. }\end{array}$} \\
\hline
\end{tabular}

\section{DISCUSSION}

The results of previous studies suggest that SLNB is associated with less morbidity than ALND (Kissin et al, 1986; Kuehn et al, 2000; Erickson et al, 2001; Burak et al, 2002; Veronesi U et al, 2003; Purushotham et al, 2005; Mansel et al, 2006; Del Bianco et al, 2008; Dabakuyo et al, 2009; Gill, 2009; Wang et al, 2011), but the comparative effects of these two approaches on tumour recurrence, patient survival and QoL with long follow-up data are still unclear. To our knowledge, no prospective study has assessed QoL after axillary surgery for BC with a long follow-up. Published studies with long-term follow-up stopped monitoring patients 3 years after surgery (Kootstra et al, 2008; Kootstra et al, 2010; Land et al, 2010). The aim of this pragmatic prospective multicentre study was to assess long-term QoL over a period of 6 years in women with BC who underwent ALND, SLNB or SLNB followed by ALND.

During follow-up, $12 \%$ of patients died, with a greater proportion of deaths among those treated with ALND (72\%). The higher mortality in the ALND group may be related to the larger tumour size seen in this group at baseline. It is well known that tumour size is an important prognostic factor in BC. Our study was designed to assess routine surgical procedures. The choice between ALND and SLNB was made by surgeons according to ASCO recommendations and according to their usual practice in their centre. Differences between surgical groups may result from the indication for SLNB for small tumours. Despite these differences, QoL scores at baseline were similar. 
Table 5. Long-term effect of surgical procedure and factors affecting arm symptoms in breast cancer patients

\begin{tabular}{|c|c|c|}
\hline & \multicolumn{2}{|c|}{ Arm symptoms } \\
\hline & Beta (s.e.) & $\boldsymbol{P}$ \\
\hline Constant & $19.8(6)$ & 0.0011 \\
\hline Follow-up & & $<0.0001$ \\
\hline Before surgery & Reference & \\
\hline After surgery & $12.6(2.2)$ & $<0.0001$ \\
\hline 6 Months after surgery & $12.6(2.1)$ & $<0.0001$ \\
\hline 12 Months after surgery & $13.2(2.1)$ & $<0.0001$ \\
\hline 72 Months after surgery & $15.5(2.1)$ & $<0.0001$ \\
\hline Axillary dissection type & & $0.22^{\mathrm{a}}$ \\
\hline ALND & Reference & \\
\hline SLNB & $3.1(3.1)$ & 0.32 \\
\hline $\mathrm{SLNB}+\mathrm{ALND}$ & $2.4(4.2)$ & 0.56 \\
\hline $\begin{array}{l}\text { Interaction follow-up time and surgical } \\
\text { procedure }\end{array}$ & & $0.04^{\mathrm{a}}$ \\
\hline After surgery and SLNB & $-7.6(3.1)$ & 0.01 \\
\hline After surgery and (SLNB + ALND) & $-5.1(4.9)$ & 0.29 \\
\hline After surgery and ALND & Reference & \\
\hline 6 Months after surgery and SLNB & $-6.1(3)$ & 0.04 \\
\hline 6 Months after surgery and (SLNB + ALND) & $-2.2(4.6)$ & 0.63 \\
\hline 6 Months after surgery and ALND & Reference & \\
\hline 12 Months after surgery and SLNB & $-9(3)$ & 0.003 \\
\hline 12 Months after surgery and (SLNB + ALND) & $-0.7(4.6)$ & 0.88 \\
\hline 12 Months after surgery and ALND & Reference & \\
\hline 72 Months after surgery and SLND & $-10.8(2.9)$ & 0.0002 \\
\hline 72 Months after surgery and (SLNB + ALND) & $-5.3(4.5)$ & 0.24 \\
\hline 72 Months after surgery and ALND & Reference & \\
\hline Lymphedema & & $<0.0001$ \\
\hline Yes & Reference & \\
\hline No & $-13.4(3.2)$ & $<0.0001$ \\
\hline \multicolumn{3}{|l|}{ Hormone therapy } \\
\hline Yes & Reference & \\
\hline No & $-3.9(2)$ & 0.049 \\
\hline \multicolumn{3}{|c|}{$\begin{array}{l}\text { Abbreviations: ALND = axillary lymph node dissection; SLNB = sentinel lymph node biopsy } \\
\text { NB: Multivariable analyses were adjusted for hospitals, hormone status, the Scarff Bloom } \\
\text { and Richardson grade, treaments (the type of surgery, adjuvant chemotherapy, hormone } \\
\text { therapy), the occurrence of lymphedema and tumour size. } \\
\text { a Overall effect. }\end{array}$} \\
\hline
\end{tabular}

As regards the treatments, the frequencies of radiotherapy and breast reconstruction were not statistically different whatever the surgical treatment groups. However, patients who underwent SLNB were more often treated with conservative surgery, without adjuvant chemotherapy and without adjuvant hormone therapy. Differences between treatments may also be due to the difference in tumour size seen between treatment groups at baseline. Moreover, whatever the surgical procedure, patients with tumour smaller than $10 \mathrm{~mm}$ had better global health than those with tumours larger than $20 \mathrm{~mm}$. Taking into account Osoba et al's (1998) conclusion about clinical difference, namely that a fivepoint difference in QoL scores is considered the minimum clinically important difference, this statistical difference $(M D=7)$ should have clinical repercussions. Patients with larger tumours were probably treated more aggressively than those with smaller tumours and this can have a negative effect on their overall health.

The results of this study also showed that, whatever the surgical procedure, premenopausal patients had higher breast symptoms scores than postmenopausal women $(\mathrm{MD}=4)$ and patients treated without hormone therapy had lower arm symptoms scores than those treated with hormone therapy $(\mathrm{MD}=-3.9)$. However, these differences were too small to have a significant clinical impact (Osoba et al, 1998). One striking finding was the beneficial effects of SLNB in comparison with ALND for arm symptoms in patients with BC 5 to 6 years after diagnosis. Moreover, compared with ALND patients, SLNB patients gradually had less pain as time passed. Although the beneficial effect of SLNB in reducing arm morbidity after surgery is well known, this is the first study to report the outcomes after SLNB or ALND with such a long followup. These results also confirmed our previous findings (Dabakuyo et al, 2009) that there was no difference for arm symptoms, between patients treated with ALND and those treated with SLNB followed by complementary ALND. This result remained 5 to 6 years after diagnosis.

In this study, the occurrence of lymphedema was responsible for arm morbidity, which affected the arm dimension of QoL. Indeed, patients with lymphedema had very high scores for arm symptoms in comparison with those without lymphedema. None of the patients of the SLNB group developed lymphedema during followup. In comparison, $10.3 \%$ of the ALND group and $7 \%$ of the ALND + SLNB group developed lymphedema. This could explain the better QoL in the SLNB group for arm symptoms.

Another finding was that body image was better 5 to 6 years after diagnosis in patients treated with SLNB. One explanation could be that, in this study, patients who underwent SLNB were more often treated with conservative surgery due to the smaller tumour size in this group than were patients in the ALND and SLNB + ALND groups. Systemic therapy side effects and upset by hair loss QoL dimensions were also better in patients in the SLNB group, who were less often treated with adjuvant chemotherapy and with adjuvant hormone therapy, which may cause side effects and hair loss. Finally, the smaller tumour size and the less aggressive treatment led to better future perspectives in the SLNB group.

The relapse rate in the different surgical groups was similar 5 to 6 years after surgery. As pointed out by Wang et al (2011) in a recent meta-analysis of randomised controlled trials that compared the effectiveness and safety of SLNB with ALND, there was no significant difference between the SLNB and ALND groups for regional recurrence whether the SLNB was positive or negative. Therefore, SLNB can thus be recommended as a safe and acceptable method for the accurate identification of early-stage $\mathrm{BC}$ without involvement of the axillary lymph nodes.

\section{ACKNOWLEDGEMENTS}

We thank Patricia LAPIERRE for collecting the data and Philip BASTABLE for correcting the manuscript.

\section{CONFLICT OF INTEREST}

The authors declare no conflict of interest.

\section{REFERENCES}

Aaronson NK, Ahmedzai S, Bergman B, Bullinger M, Cull A, Duez NJ, Filiberti A, Flechtner H, Fleishman SB, de Haes JC et al. (1993) The European Organisation for Research and Treatment of Cancer QLQ-C30: 
a quality-of-life instrument for use in international clinical trials in oncology. J Natl Cancer Inst 85: 365-376.

Akaike Hirotugu (1974) A new look at the statistical model identification. IEEE Trans Auto Control 19(6): 716-723.

Burak WE, Hollenbeck ST, Zervos EE, Hock KL, Kemp LC, Young DC (2002) Sentinel lymph node biopsy results in less postoperative morbidity compared with axillary lymph node dissection for breast cancer. Am J Surg 183(1): 23-27.

Dabakuyo TS, Fraisse J, Causeret S, Gouy S, Padeano MM, Loustalot C, Cuisenier J, Sauzedde JM, Smail M, Combier JP, Chevillote P, Rosburger C, Boulet S, Arveux P, Bonnetain F (2009) A multicenter cohort study to compare quality of life in breast cancer patients according to sentinel lymph node biopsy or axillary lymph node dissection. Ann Oncol 20: 1352-1361.

Del Bianco P, Zavagno G, Burelli P, Burelli P, Scalco G, Barutta L, Carraro P, Pietrarota P, Meneghini G, Morbin T, Tacchetti G, Pecoraro P, Belardinelli V, De Salvo GL. GIVOM (2008) Morbidity comparison of sentinel lymph node biopsy versus conventional axillary lymph node dissection for breast cancer patients: results of the sentinellaGIVOM Italian randomised clinical trial. Eur J Surg Oncol 34(5): 508-513.

Erickson VS, Pearson ML, Ganz PA, Adams J, Kahn KL (2001) Arm edema in breast cancer patients. J Natl Cancer Inst 93(2): 96-111.

Ferlay J, Autier P, Boniol M, Heanue M, Colombet M, Boyle P (2007) Estimates of the cancer incidence and mortality in Europe in 2006 Ann Oncol 18(3): 581-592.

Fisher B, Anderson S, Bryant J, Margolese RG, Deutsch M, Fisher ER, Jeong JH, Wolmark N (2002) Twenty-year follow-up of a randomized trial comparing total mastectomy, lumpectomy, and lumpectomy plus irradiation for the treatment of invasive breast cancer. N Engl J Med 347: $1233-1241$.

Gill G (2009) Sentinel-lymph-node-based management or routine axillary clearance? One-year outcomes of sentinel node biopsy versus axillary clearance (SNAC): a randomized controlled surgical trial. Ann Surg Oncol 16(2): 266-275.

Jacobson JA, Danforth DN, Cowan KH, d'Angelo T, Steinberg SM, Pierce L, Lippman ME, Lichter AS, Glatstein E, Okunieff P (1995) Ten-year results of a comparison of conservation with mastectomy in the treatment of stage I and II breast cancer. N Engl J Med 332(14): 907-911.

Kissin MW, Querci della Rovere G, Easton D, Westbury G (1986) Risk of lymphoedema following the treatment of breast cancer. Br J Surg 73(7): 580-584.

Kootstra J, Hoekstra-Weebers J, Rietman H, de Vries J, Baas P, Geertzen JH, Hoekstra HJ (2008) Quality of life after sentinel lymph node biopsy or axillary lymph node dissection in stage I/II breast cancer patients: a prospective longitudinal study. Ann Surg Oncol 15(9): 2533-2541.

Kootstra J, Hoekstra-Weebers J, Rietman H, de Vries J, Baas PC, Geertzen JH, Hoekstra HJ (2010) A longitudinal comparison of arm morbidity in stage I-II breast cancer patients treated with sentinel lymph node biopsy, sentinel lymph node biopsy followed by completion lymph node dissection, or axillary lymph node dissection. Ann Surg Oncol 17: 2384-2394.

Krag DN, Weaver DL, Alex JC, Fairbank JT (1993) Surgical resection and radiolocalization of the sentinel lymph node in breast cancer using a gamma probe. Surg Oncol 2(6): 335-339.

Kuehn T, Klauss W, Darsow M, Regele S, Flock F, Maiterth C, Dahlbender R, Wendt I, Kreienberg R (2000) Long-term morbidity following axillary dissection in breast cancer patients-clinical assessment, significance for life quality and the impact of demographic, oncologic and therapeutic factors. Breast Cancer Res Treat 64(3): 275-286.
Lacour J, Le M, Caceres E, Koszarowski T, Veronesi U, Hill C (1983) Radical mastectomy versus radical mastectomy plus internal mammary dissection. Ten year results of an international cooperative trial in breast cancer. Cancer 51: 1941-1943.

Land SR, Kopec JA, Julian TB, Brown AM, Anderson SJ, Krag DN, Christian NJ, Costantino JP, Wolmark N, Ganz PA (2010) Patient-reported outcomes in sentinel node-negative adjuvant breast cancer patients receiving sentinel-node biopsy or axillary dissection: national surgical adjuvant breast and bowel project phase III protocol B-32. J Clin Oncol 28(25): 3929-3936.

Lyman GH, Giuliano AE, Somerfield MR, Benson 3rd AB, Bodurka DC, Burstein HJ, Cochran AJ, Cody 3rd HS, Edge SB, Galper S, Hayman JA, Kim TY, Perkins CL, Podoloff DA, Sivasubramaniam VH, Turner RR, Wahl R, Weaver DL, Wolff AC, Winer EP. American Society of Clinical Oncology (2005) American Society of Clinical Oncology Guideline Recommendations for sentinel lymph node biopsy in early-stage breast cancer. J Clin Oncol 23(30): 7703-7720.

Maddox WA, Carpenter Jr JT, Laws HL, Soong SJ, Cloud G, Urist MM, Balch CM (1983) A randomized prospective trial of radical (Halsted) mastectomy versus modified radical mastectomy in 311 breast cancer patients. Ann Surg 198: 207-212.

Mansel RE, Fallowfield L, Kissin M, Goyal A, Newcombe RG, Dixon JM, Yiangou C, Horgan K, Bundred N, Monypenny I, England D, Sibbering M, Abdullah TI, Barr L, Chetty U, Sinnett DH, Fleissig A, Clarke D, Ell PJ (2006) Randomized multicenter trial of sentinel node biopsy versus standard axillary treatment in operable breast cancer: the ALMANAC Trial. J Natl Cancer Inst 98(9): 599-609.

McCready D, Holloway C, Shelley W, Down N, Robinson P, Sinclair S, Mirsky D. Breast Cancer Disease Site Group of Cancer Care; Ontario's Program in Evidence-Based Care (2005) Surgical management of early stage invasive breast cancer: a practice guideline. Can J Surg 48: 185-194.

Osoba D, Rodrigues G, Myles J, Zee B, Pater J (1998) Interpreting the significance of changes in health-related quality-of-life scores. J Clin Oncol 16(1): 139-144.

Purushotham AD, Upponi S, Klevesath MB, Bobrow L, Millar K, Myles JP, Duffy SW (2005) Morbidity after sentinel lymph node biopsy in primary breast cancer: results from a randomized controlled trial. J Clin Oncol 23(19): 4312-4321.

Sant M, Allemani C, Santaquilani M, Knijn A, Marchesi F, Capocaccia R. EUROCARE Working Group EUROCARE-4 (2009) Survival of cancer patients diagnosed in 1995-1999. Results and commentary. Eur J Cancer 45: 931-991.

Veronesi U, Paganelli G, Viale G, Luini A, Zurrida S, Galimberti V, Intra M, Veronesi P, Robertson C, Maisonneuve P, Renne G, De Cicco C, De Lucia F, Gennari R (2003) A randomized comparison of sentinel-node biopsy with routine axillary dissection in breast cancer. $N$ Engl J Med 349(6): 546-553.

Vervoort MM, Draisma G, Fracheboud J, de Koning HJ, van de Poll-Franse LV, de Koning HJ (2004) Trends in the usage of adjuvant systemic therapy for breast cancer in the Netherlands and its effect on mortality. $\mathrm{Br} J$ Cancer 91(2): 242-247.

Wang Z, Wu LC, Chen JQ (2011) Sentinel lymph node biopsy compared with axillary lymph node dissection in early breast cancer: a meta-analysis. Breast Cancer Res Treat 129: 675-689.

This work is published under the standard license to publish agreement. After 12 months the work will become freely available and the license terms will switch to a Creative Commons AttributionNonCommercial-Share Alike 3.0 Unported License. 